\title{
Community Forest Brigades and their implementation as part of a new vision in the integrated fire management in the Bolivarian Republic of Venezuela
}

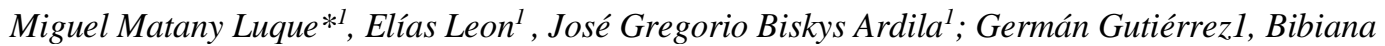 \\ Bilbao $^{2}$, Roberto Rivera-Lombardi ${ }^{3}$; Adriana Millán ${ }^{1,4}$
}

\author{
${ }^{1}$ Cuerpo de Bomberos Forestales, Instituto Nacional de Parques (INPARQUES), *mmatany@yahoo.com; \\ ${ }^{2}$ Universidad Simón Bolívar, \\ ${ }^{3}$ Universidad Central de Venezuela, Caracas, Venezuela y \\ ${ }^{4}$ Centro de Investigación y Transferencia Rafaela, Universidad Nacional de Rafaela - CONICET, Argentina
}

\begin{abstract}
Venezuela is located in the Neotropical area of the planet, a region where climate change scenarios involve a worsening of drought and an increase in temperatures, with the consequent increase in the season and severity of vegetation fires. Additionally, the occurrence of socio-productive activities based on the use of fire in or around many National Parks is a constant fact. Thus, the use of fire in these areas cannot be replaced in the short or medium term, even in those conservation areas, since their indigenous inhabitants make use of fire as part of their cultural legacy. Given the vulnerability of the ecosystems of the National Park System, which includes fire-sensitive vegetation such as forests, new challenges arise, forcing the replacement of formerly established suppression and combat models and developing new, more effective fire management strategies nationwide.From 2010, several initiatives promoted the incorporation of Integrated Fire Management practices (IFM) into new management policies of the Forest Fire Department. These policies include the inclusion of community members, their traditional knowledge and practices about fire management, and scientific criteria, as to achieve an effective reduction of the area affected by fires. This strategy involved the promotion, organization, training and equipment of Community Forest Brigades that integrate voluntarily to the National Risk Management System. This strategy has had a positive impact on the reduction of the forest area affected by fire while contributing to strengthening the culture of self-protection in remote rural communities. The training process and the experience accumulated in Waraira Repano National Park (La Costa Mountain Range, Capital Region), Mochima National Park (Northeast coastal Region), El Guácharo National Park (La Costa Mountain Range, Eastern Chain), and especially in Canaima National Park (Guayana Shield - South Region), have set the foundations for the promotion of a national strategy. The bases of this intercultural strategy include rural communities as central characters in the formulation and development of Local Fire Management Plans in the whole country.
\end{abstract}

Keywords: self-protection, local community management, community fire risk management, integrated fire management, community forest brigades. 